\title{
Modelling storm responses on a high-energy coastline with XBeach
}

\author{
J. J. Williams ${ }^{1}$ (D) L. S. Esteves ${ }^{2} \cdot$ L. A. Rochford ${ }^{3}$
}

Received: 5 January 2015 / Accepted: 4 May 2015/Published online: 16 May 2015

(c) Springer International Publishing Switzerland 2015

\begin{abstract}
The XBeach model has been used to simulate the morphological impacts of storms on sandy and gravel beaches. Taking as a case study Rossbeigh Spit located on the high-energy coast of western Ireland, the study reported here tests the capacity of XBeach to reproduce barrier breaching during a storm in December 2008. It demonstrates that predictions of the breaching event agree reasonably well with observations. However, the main focus of the paper is to establish using the model results, sitespecific critical wave and water level conditions giving rise to dune erosion, overwashing and breaching. By deriving simple-to-use expressions to define hydrodynamic thresholds the study advances the ability to predict the impacts of infrequent and rarely observed storm events and is considered to provide useful coastal management tool for assessing the vulnerability of sandy barriers to breaching high-energy during storms.
\end{abstract}

Keywords XBeach · Rossbeigh spit · High-energy coast · Storm breaching $\cdot$ Threshold conditions

\section{J. J. Williams}

jon.williams@mottmac.com

1 Mott MacDonald House, 8-10 Sydenham Road, Croydon CR0 2EE, UK

2 Bournemouth University, Talbot Campus, Poole, Dorset BH12 5BB, UK

3 Aberdeen Council, Carlton House, Arduthie Road, Stonehaven AB39 2QP, UK

\section{Introduction}

Sandy barrier beaches frequently provide a degree of protection to infrastructure, property and habitat from large waves and high water levels during storms (Bird 1985; Larson et al. 2004). Erosion of these coastal features potentially makes them more vulnerable to overtopping and breaching and may increase the risk of coastal flooding. This risk may be elevated further by sea level rise and the occurrence of more frequent and more intense storms due to climate change. To improve coastal planning and management it is essential to develop robust tools that enable accurate prediction of barrier system responses to single storms and to storm sequences for present and future climatic conditions ( $c f$. Stockdon et al. 2007). However, the majority of work undertaken in this field has investigated moderate or low energy coasts (e.g. Sánchez-Arcilla and Jiménez 1994; Terchunian and Merkert 1995; Kraus and Wamsley 2003; Giese et al. 2009; Van Thiel de Vries 2009; Gracia et al. 2013) and few studies have looked at the high-energy exposed coasts of western Europe (e.g. Sala 2010, O'Shea and Murphy 2013).

Cooper et al. (2004) argue that beaches and dunes that are exposed frequently to high-energy wave regimes require extreme storms to cause significant morphological impact. With reference to the high-energy compartmentalised beaches of western Ireland they further observe that uncertainty about the nature of the storms required to generate morphological change makes the assessment of storm impacts difficult.

With rare exceptions, dissipative beaches generally exposed to high-energy wave conditions exhibit little net morphological change in response to enhanced wave and tidal conditions. Cooper et al. (2004) suggest that for storms to have any significant morphological impact on the 
high-energy beaches, they must be: (a) directed onshore; (b) coincident with high (spring) tide; and (c) sufficiently energetic to mobilise large quantities beach sediments. The probability of coincident high water levels during spring tides and large waves, and thus the magnitude of the storm impact, is also related to the duration of a storm. However, this is not a simple relationship as demonstrated by storm records. For example, on the west coast of Ireland, only a small number of recorded onshore directed storms coincide with spring tides (c. 10 between 1957 and 1988), and not all of these storms had an erosional impacts on the shoreline. Cooper et al. (2004) suggest that this is almost certainly linked to site-specific dynamic impact thresholds.

The authors identify four characteristics that act individually or collectively to constrain the morphological response of exposed sandy coasts in Ireland to storms: (a) the available sediment volume is fixed with no contemporary sediment supply; (b) resistant headlands confine sediments; (c) beaches are dissipative and exhibit equilibrium plan forms; and (d) beaches are backed by high, vegetated Holocene dunes. They propose two models of storm response on dissipative beaches: (1) when near-spring high tide water levels are elevated by small surges, swell, and in some cases, short period waves generated locally by strong winds are able to undercut dunes resulting in erosion and cross-shore and/or alongshore transport of sediment (e.g. Hurricane Debbie, 1961); and (2) the occurrence of strong winds directed at an oblique angle to the shore for sustained periods can result in beach erosion and steepening which in turn allows subsequent swell to further erode the dunes as a new equilibrium beach profile is established. In addition, and of special relevance to the present study of Rossbeigh, is the temporary sediment storage role of the ebb tidal bar during storms (cf. Orford et al. 1999).

Abrupt changes in the coastal morphology brought about by storms can be viewed as being reversible if the system can repair itself during normal conditions. The changes are irreversible when the new morphology changes hydrodynamic and sediment regimes to such an extent that recovery of the feature back to its former profile is impossible, at least within an immediate (less than decadal) timeframe. Although research into barrier and inlet dynamics in Ireland has been reported (e.g. O'Shea and Murphy 2013), the combined wave and tidal threshold conditions resulting in breaching remain largely undefined. Further, since storm impacts are rarely observed and difficult to predict, Cooper et al. (2004) recommend that studies involving direct observations and/or detailed numerical simulations are required to identify the combination of storm attributes necessary to produce a morphological response.

With this in mind, using the breaching of the exposed high-energy Rossbeigh Spit beach in western Ireland as a case study, this paper uses available data and the processbased nearshore numerical XBeach model Version 18 (Roelvink et al. 2006, 2010) to examine the hydrodynamic conditions leading to the breach. The modelling study simulates the damaging storm of 13-14 December 2008 before quantifying hydrodynamic threshold conditions defining dune recession, overwashing and breaching brought about by varying storm scenarios. While data relating to topography, bathymetry and sediment properties at Rossbeigh are scarce and of limited temporal and spatial resolution, the site nevertheless is valuable for a modelling study since storm breaching events are rarely observed and consequently little studied. Further, if the model can be shown to simulate the broad-scale morphological impacts of an observed breach event, its outputs may have further utility in providing effective coastal management tools that can be used to assist understanding and prediction of potential future coastal changes due to sea level rise and other climate related changes in forcing conditions.

\section{Field site: Rossbeigh, Ireland}

Located in Dingle Bay, County Kerry, Ireland, Rossbeigh and Inch are two mid-bay barrier beaches on a coastline bounded by rocky cliffs (Fig. 1). This barrier beach system encloses Inner Dingle Bay to form the Castlemaine Harbour estuary which also contains a third barrier, Cromane Point. From the mainland, Rossbeigh extends northwards and is relatively stable and swash aligned for approximately $2.6 \mathrm{~km}$. Further north, the orientation of Rossbeigh changes and becomes drift aligned and has been subjected to strong erosion during the period 1998-2008. Inch and Rossbeigh are separated by a tidal inlet $c .2 \mathrm{~km}$ wide where flow speeds exceed $1 \mathrm{~m} / \mathrm{s}$. Well-developed ebb tidal bars are present on the north and south seaward side of the inlet. The width of present day Rossbeigh varies

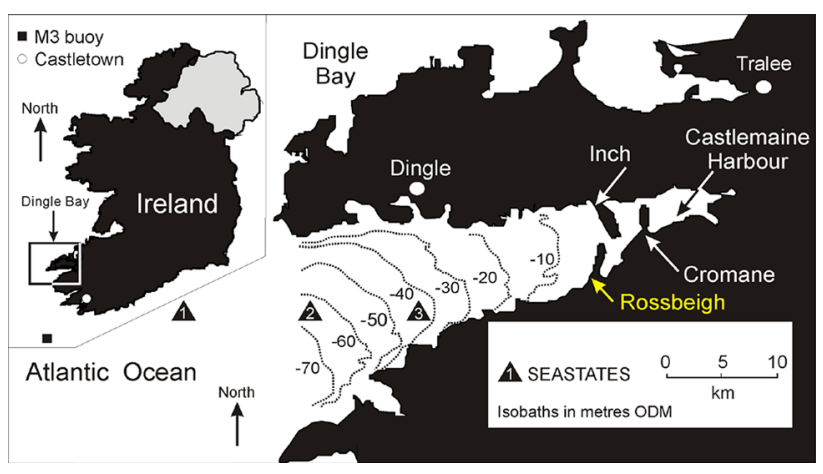

Fig. 1 a Location of the field site, Dingle Bay, County Kerry, Ireland. Also shown are: the data extraction locations for SEASTATES; and the location of the M3met buoy and the Castletown tidal prediction site 
between 100 and $600 \mathrm{~m}$ and vegetated dunes are present along most of the spit.

The spit is founded on underlying cobble or gravel deposits, with the coarser materials acting as an anchor upon which the finer sediments move. Dune heights in the south of Rossbeigh range between 12 and $17 \mathrm{~m}$ above Ordnance Datum Malin (ODM). In the north, the dune heights decline to values between 5 and $12 \mathrm{~m}$ ODM. The spit has no infrastructure or coastal structures and consists of sandy and coarse sediments from both fluvial and glacial sources (Carter 1988; O'Shea et al. 2011). With the exception of gravel-size sediments comprising the storm beach at the southern end of Rossbeigh, the beach is composed of sediment with $D_{50}$ and $D_{90}$ of 0.235 and $0.341 \mathrm{~mm}$, respectively (Sala 2010). Due to exposure to modally highenergy, fully-refracted swell and the availability of sandy sediment, Inch and Rossbeigh are characterised by shallow cross-shore gradients and can be classified as unbarred, dissipative, flat and featureless where spilling breakers are dominant (Masselink and Short 1993). Typically, Rossbeigh has a relative tidal range (RTR) of 2.9 and dimensionless fall velocity $(\Omega)$ value of 6 (Gourlay 1968).

In common with other locations on the western coastline of Ireland Rossbeigh is subjected to high modal wave and wind energy levels and also lies in the path of several common storm tracks (Cooper et al. 2004; Lozano and Devoy 2000; Lozano et al. 2004). The main exposure of the Dingle embayment is to the southwest. The wave conditions that exist at Rossbeigh are dominated by Atlantic swell which propagates into Dingle Bay and has a peak period of around $16 \mathrm{~s}$. The mean spring and neap tidal ranges are 3.2 and $1.5 \mathrm{~m}$, respectively. The modal wave climate for Dingle bay is characterised by a peak period, $T_{p}$, of $7 \mathrm{~s}$, a mean significant wave height, $H_{s}$, of $2.4 \mathrm{~m}$ and a mean direction, $\theta$, of $260^{\circ}$ (Sala 2010; O'Shea et al. 2011). Refraction and dissipation reduces wave energy to low levels along the shoreline of Inch and Rossbeigh. Although during storms $\theta$ remains approximately the same as the fair weather value, $T_{p}$ and $H_{s}$ values around the entrance to Dingle Bay are more typically $13.6 \mathrm{~s}$ and $6.6 \mathrm{~m}$, respectively. Wave energy dissipation is concentrated on the ebb tidal bars and the distal beaches of Rossbeigh and Inch. The proximal margins of Rossbeigh and Inch remain sheltered from the impact of larger swell (Cooper et al. 2004). During extreme storms, (e.g. Hurricane Debbie 1961), the bulk of incoming wave energy is dissipated on the frontal margins of the ebb tidal bars (Cooper et al. 2004).

Owing to effective cross-shore wave energy dissipation, changes in sediment transport patterns may not necessarily follow an increase in swell size as the surf zone fronting Rossbeigh expands to accommodate the larger incoming wave energy. The offshore morphology (e.g. ebb tidal bar features) contributes further to energy dissipation during storms. However, storm enhancement by wave setup, enhanced secondary wave-induced flows and infragravity motions may contribute to coastal impacts over and above those associated with gravity waves alone. Rossbeigh and Inch are backed by well-developed dune systems which are of sufficient size at most locations to prevent overwash. In most cases the morphological response of Rossbeigh and Inch to storms is restricted to cross-shore and/or alongshore transport of sediment, primarily by wave action and to aeolian deflation and transport.

Based on historical evidence it is thought that the swash platform located offshore from the northern section of Rossbeigh is maintained with a cross-shore supply of sediment originating primarily from the southern ebb shoal deposits at the entrance to the estuary (O'Shea et al. 2011). In addition, there is evidence that some sediment is supplied by littoral drift from the south. Observed changes in the position of the main estuary channel can lead to a reduction in supply and result in erosion of the swash platform as seen in the period 2000-2008. During this period, the erosion increasingly exposed Rossbeigh to damaging waves during storms leading eventually to the breaching during 13-14 December 2008 described below. Evidence from other breach events (e.g. Kraus and Wamsley 2003; Sánchez-Arcilla and Jiménez 1994) indicates that once breaching has occurred, the resulting sediment deposits in the back barrier areas are available to be re-worked and transported seawards to the ebb shoal by existing channels. Here they can once again supply the swash platform and provide the degree of protection to Rossbeigh necessary to allow natural repair of the breach through beach and dune re-construction. However, since December 2008, there is little evidence that this process is occurring quickly at Rossbeigh.

\section{Rossbeigh breach of 13-14 December, 2008}

Oblique aerial images of Rossbeigh in 2003 (pre-breach) and 2010 (post-breach) are shown in Fig. 2a, b, respectively and Google Earth images of Rossbeigh in 2003 (prebreach) and 2010 (post-breach) are shown in Fig. 2c, d, respectively. The 13-14 December 2008 breach event followed a 10 year period of intensive erosion and marked a significant change in the morphology of the barrier system and in the hydrodynamics of the estuary behind the barrier. Had erosion not been so severe, it is unlikely that the event of 13-14 December 2008 would have resulted in the breach.

In order to understand the circumstances leading to the Rossbeigh breach during 13-14 December 2008, Sala (2010), O'Shea et al. (2011) and O'Shea and Murphy (2013) have analysed historical maps and aerial 
Fig. 2 a Oblique aerial view of Rossbeigh pre-breach circa 2003; b oblique aerial view of Rossbeigh post-breach circa 2010; c Google Earth image of Rossbeigh August 2003; and d Google Earth image of Rossbeigh August 2010 showing the breach
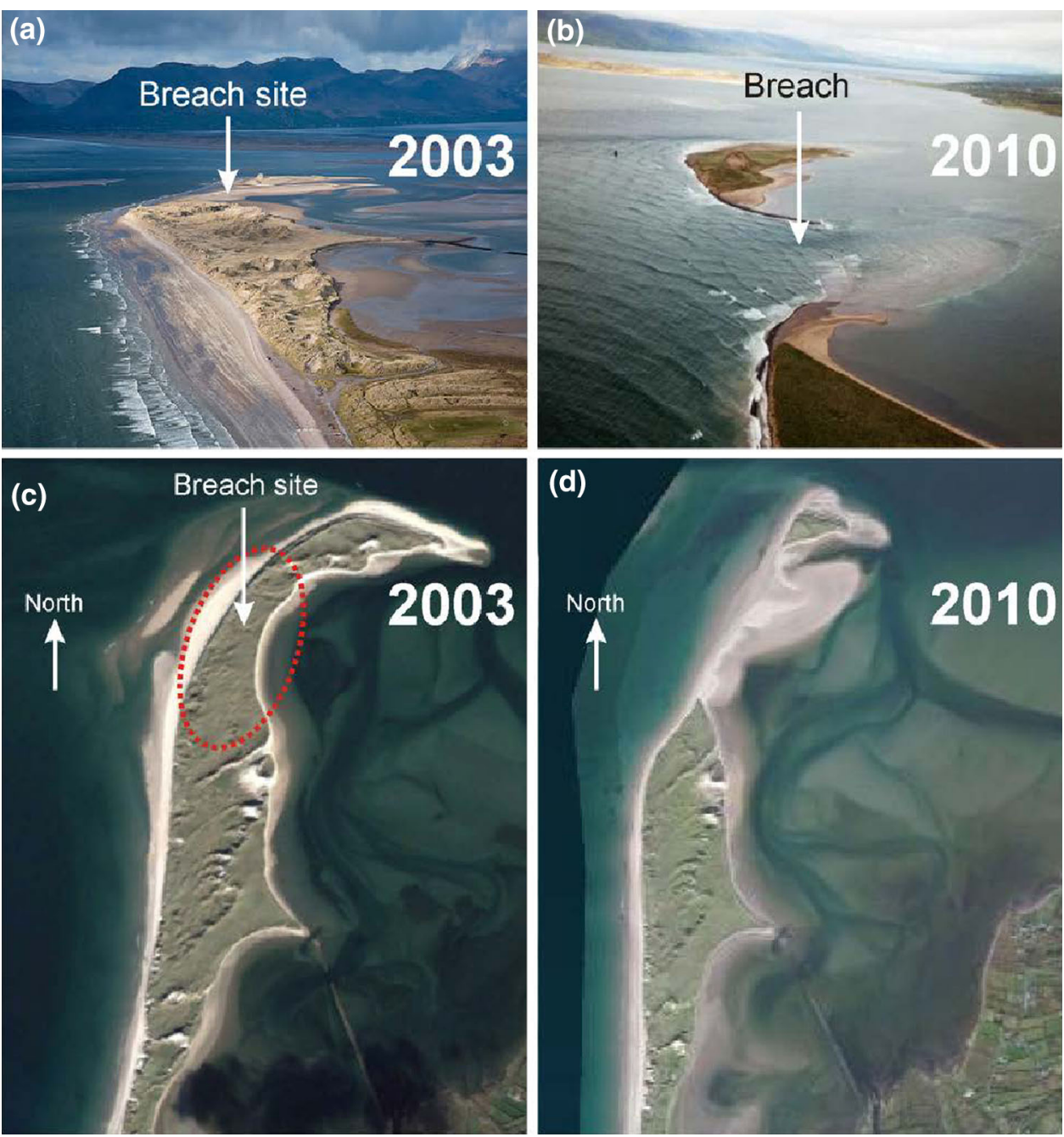

photographs. Their analysis identified that the period 2004-2009 had a higher than average concentration of winter storms and recognised an important interdependency between the inlet channel, the ebb tidal bar and the beach. The most significant events leading to the breach can be summarised as follows: (a) around 2000, the inlet channel flowed in an ' $S$ ' shape, depositing sediment onto the ebb tidal bar which acted to both protect the distal end of Rossbeigh from waves and to supply the beaches with sediment; (b) in the period 2000-2006, the inlet channel became progressively straighter resulting in sediment being transported into deeper water out into Dingle Bay where it was less available to the ebb tidal bar and the beach. During this period dune recession rates of up to $12 \mathrm{~m} / \mathrm{yr}$ were observed around the spit recurve location (the volume of dune sediment displaced was $c$. 52,000 $\mathrm{m}^{3} / \mathrm{yr}$, O'Shea et al. 2011); (c) the reduction in sediment supply resulted in accelerated erosion north of the recurve point; and (d) erosion of the swash bar between 2006 and 2008 reduced the ability of the distal end of Rossbeigh to withstand storm waves. The loss of dune volume reached a maximum of $530,000 \mathrm{~m}^{3} / \mathrm{yr}$ in 2008 and culminated in the 13-14 December 2008 breach which left a small northern island separated by around $500 \mathrm{~m}$ from the southern dune systems at high water (Fig. 2b, d).

This evidence supports the view that the 13-14 December 2008 breach event resulted from a breach mechanism described by Kraus (2003) where the reduction of sediment supplied results in the narrowing and lowering of the barrier and eventual breaching. Indeed the 13-14 December 2008 storm was not exceptional and its effectiveness must be attributed in part to the antecedent erosion accomplished by numerous proceeding storm events during the period 1998-2008. On this basis Sala (2010) argued that the evidence of swash platform erosion at Rossbeigh indicates that the breach event most likely resulted from a decline in beach volume rather than from the direct impact of one or more storm events. Since the breach, erosion rates on Rossbeigh have continued to increase and the ebb tidal bars have continued to grow (O'Shea et al. 2011; O'Shea 
and Murphy 2013). The breach is currently around $800 \mathrm{~m}$ wide. O'Shea and Murphy 2013 suggest that if present historical trends continue erosion rates will continue to be high in the drift aligned zone and the hinge point between swash-aligned and drift-aligned zones will continue to move in the direction of the swash aligned zone, increasing the area susceptible to erosive processes. This processes is likely to increase the risk of coastal flooding and inundation in the back barrier area.

\section{Metocean conditions at the time of the breach}

At the time of the breach there are no available measurements of waves or tides in the vicinity of Rossbeigh. In order to better understand the prevailing metocean conditions during the breach, predicted wave conditions have been obtained from the ABPmer SEASTATES ${ }^{1}$ wave hindcast model at three locations in Dingle Bay (Fig. 1). In addition, predicted astronomical tidal elevation data, $h$, were obtained at the location closest to Rossbeigh at Castletown using Delft Dashboard ${ }^{2}$ (Fig. 1). As a check on the predictions from SEASTATES and Delft Dashboard, metocean data were also obtained from the Irish Marine Weather Buoy M3 located 30 nautical miles south west of Mizen Head in a water depth of $155 \mathrm{~m}\left(51^{\circ} 13^{\prime} 0^{\prime \prime} \mathrm{N}\right.$ $10^{\circ} 33^{\prime} 0^{\prime \prime} \mathrm{W}$, Fig. 1). As an additional check, these data were also compared with the Irish Marine Weather Buoy M6 located far offshore at $53^{\circ} 3^{\prime} 36^{\prime \prime} \mathrm{N} 15^{\circ} 55^{\prime} 48^{\prime \prime} \mathrm{W}$ (location not shown in Fig. 1).

For the period 2-30 December 2008, Fig. 3 shows timeseries of: (a) atmospheric pressure, $P$; (b) wind speed, $U_{w}$; and (c) wind direction, $\theta_{w}$ measured by the M3 and M6 buoys; (d) predicted astronomical tide (Delft Dashboard), $h$, (e) predicted and measured (M3 and M6 buoys) $H s$; (f) predicted mean wave period, $T m 10$; (g) predicted mean wave direction, $\theta$; and (h) predicted wave power, $W P$. In all cases the predicted data are from SEASTATES at Location 1 (Fig. 1). WP is defined as $H s^{2} \cdot \operatorname{Tm}_{10} \cdot\left(\rho g^{2} / 64 \pi\right)$, where $g$ is the acceleration due to gravity. The dates when the breach occurred (13-14 December, 2008) are shown by the grey shaded area. It is noted that although the storm on 5 December was more energetic (c. $50 \%$ more wave power), it occurred during neap tides whereas the storm causing the breach occurred during spring tides which allowed waves penetration higher up the beach profile.

It is noted that no tidal enhancement attributable to surge has been accounted for in Fig. 3. An estimate of the surge during the period 13-14 December was obtained using

\footnotetext{
${ }^{1}$ http://www.seastates.net/.

${ }^{2}$ https://publicwiki.deltares.nl/display/OET/DelftDashboard.
}

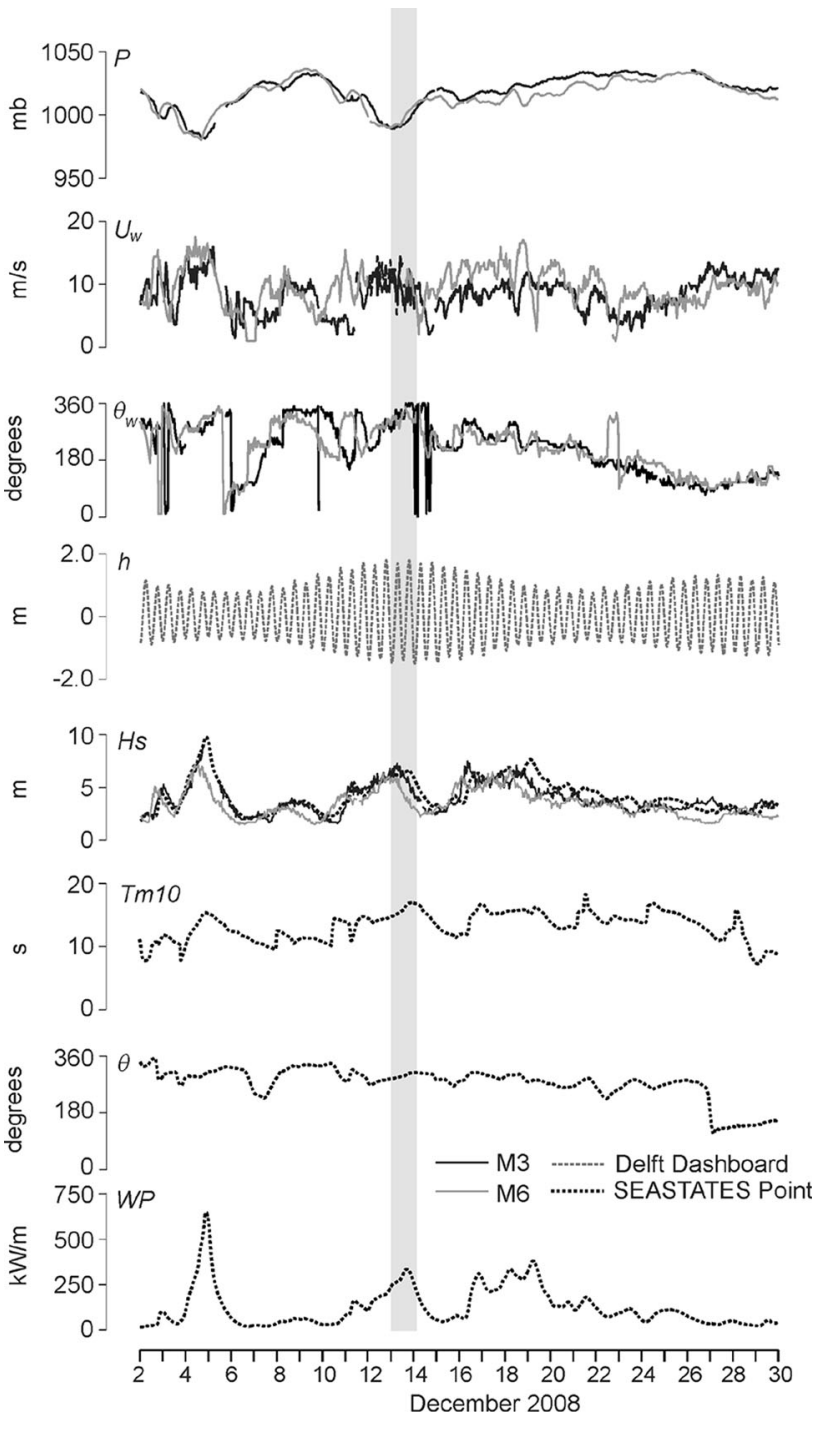

Fig. 3 Metocean date time-series for the period 2-30 December, 2008 showing: a atmospheric pressure, $P$; mean wind speed, $U_{w}$; mean wind direction, $\theta_{w}$ measured by the M3 and M6 buoys; predicted astronomical tide (Delft Dashboard), $h$; predicted and measured (M3 and M6 buoys) significant wave height, $H s$; predicted mean wave period, $\operatorname{Tm} 10$; predicted mean wave direction, $\theta$; and predicted wave power, $W P$

$\frac{\partial \eta}{\partial x}=\frac{\eta \tau_{w}}{\rho g(h+\eta)}$

where $\eta$ is the surge elevation above the still water level, $x$ is the horizontal distance, $\rho$ is the density of sea water, $g$ is the acceleration due to gravity, $h$ is the water depth and the wind stress, $\tau_{w}$, is defined as

$\tau_{w}=\rho_{a} C d_{w} W^{2}$

where $\rho_{a}$ is the density of air, $C d_{w}$ is a drag coefficient (c. $1.2 \times 10^{-6}$ ) and $W$ is the wind speed (Van Dorn 1953). Account was also taken of the inverse barometer effect with respect to the reference atmospheric pressure assumed 


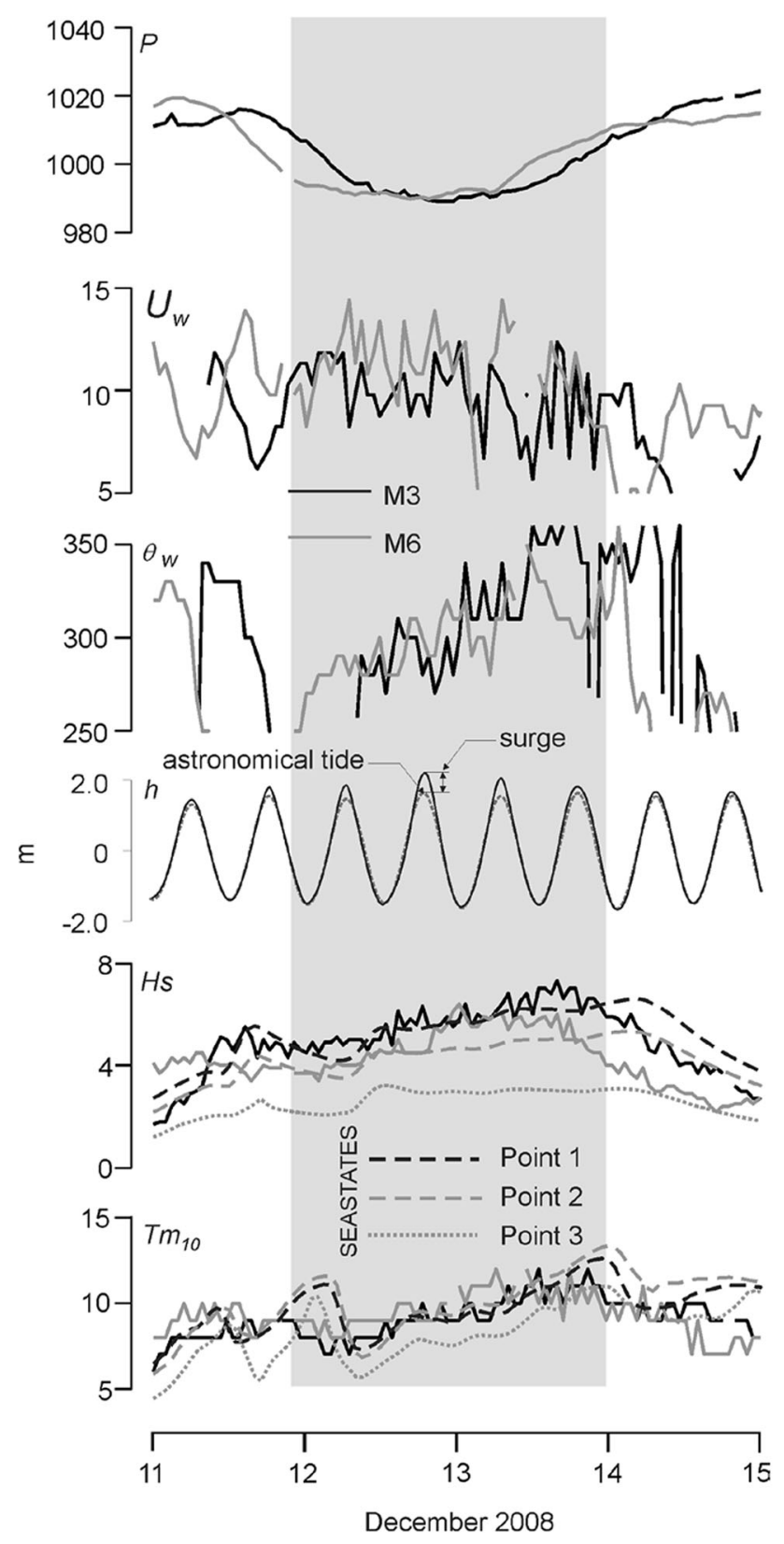

Fig. 4 Detail of metocean date time-series for the period 11-15 December, 2008 showing: atmospheric pressure, $P$, mean wind speed, $U w$, mean wind direction, $\theta w$, significant wave height, $H s$ and $T m 10$ from the M3 and M6 buoys, along with the predicted astronomical tide (Delft Dashboard), $h$ (including the surge component) and predicted $H s$ and mean wave period, Tm10 from SEASTATES at locations 1-3 (Fig. 1)

$1013.3 \mathrm{mb}$ (e.g. Dorandeu and Le Traon 1999). During the 13-14 December 2008 storm, the $P$ decreased from around $1015 \mathrm{mb}$ on 12 December to a minimum value of $989 \mathrm{mb}$ (Fig. 4) and elevated the mean water level by around $23 \mathrm{~cm}$ during the storm.

\footnotetext{
${ }^{3}$ http://www.mikebydhi.com/.
}

Data for the period 11-15 December are shown in more detail in Fig. 4. This shows time-series of: $P, U_{w}, \theta_{w}, H s$ and $T m_{10}$ from the M3 and M6 buoys along with $h$ and predicted $H s$ and $T m_{10}$ time-series from SEASTATES at locations 1-3 (Fig. 1). The surge component of the total water level is also shown in Fig. 4. The skew surge is estimated to be $0.55 \mathrm{~m}$ (i.e. water level $=4.93 \mathrm{~m}$ ODM) and approximates to a 1:5 year event (Olbert and Hartnett 2010). The breach period is indicated by the grey shaded area on the figure. With available information it is not possible to define precisely when the breach occurred. However, anecdotal evidence suggests this occurred at high tide around $2100 \mathrm{~h}$ on 13 December, 2008. The metocean time-series in Fig. 4 provide the forcing conditions used in the XBeach simulations described below.

\section{Modelling approach}

\section{Bathymetry and topography}

A problem frequently faced at many coastal locations concerns a lack of good quality bathymetric and topographic data that are needed to create accurate pre- and post-storm digital elevation models (DEMs). Here prebreach data were obtained from digitised maps, aerial photographs and the British Admiralty Nautical Chart 2789 (Dingle Bay and Smerwick Harbour). Owing to a scarcity of contemporary data for the 2008 period, it should be noted these data comprise the best possible composite of data from a range of dates between 2002 and 2008. Using aerial photographs of Rossbeigh taken in 2005-2007, and the well-defined post-breach DEM described below, the $\mathrm{MIKE}^{3}$ Zero module was used to georeference and incorporate these images into existing maps. Using this approach, visual interpretation of the terrain allowed estimation of contours around the time of the breach. It is noted that historical evidence indicates that bathymetric/topographic changes occurring to the south and north of the breach area on Rossbeigh are typically small thus supporting the view that the pre-storm DEM of these area obtained from data in the period 2005-2007 are a good representation of the pre-storm beach and dune geometry. Although it is considered likely that for areas of Rossbeigh characterised by quicker than average morphological change the resulting DEM is not an exact representation of the morphology of Rossbeigh immediately before the breach, it is sufficiently accurate to meet the objectives of the present study.

An illustration of the pre-breach DEM extending $2 \mathrm{~km} \times 0.6 \mathrm{~km}$ is shown in Fig. 5a. This is part of the larger DEM used in the XBeach model and is shown here to illustrate the primary area of investigation in this paper. 


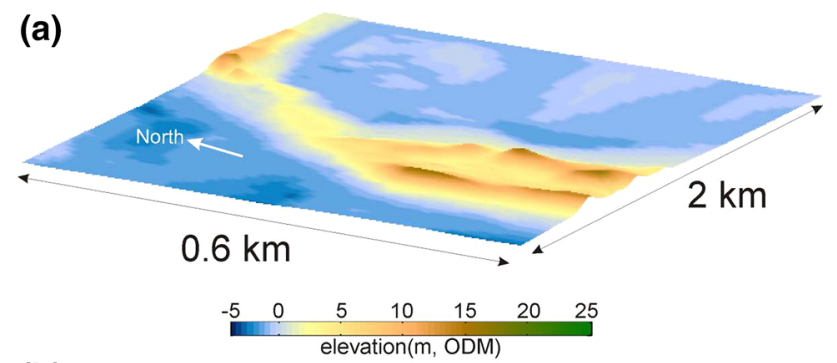

(b)

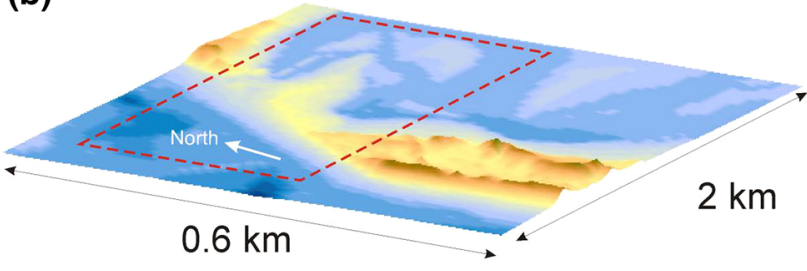

Fig. 5 a Part of the pre- 13-14 December 2008 storm DEM used in the XBeach model; and $\mathbf{b}$ part of the post-storm DEM used to validate the XBeach model. The red box denotes the breaching area

All bathymetric and topographic data are referenced to Ordnance Datum Malin (ODM).

The post-breach bathymetry and topography for Rossbeigh is well-defined using data from: (a) a multi-beam echo survey to the $10 \mathrm{~m}$ isobath; (b) MIKE Zero digitisation of images from aerial and satellite sources ( $c f$. O'Shea et al. 2011); (c) lidar data from 2011 provided by Kerry County Council; and (d) British Admiralty Nautical Chart 2789 (Dingle Bay and Smerwick Harbour). An illustration of the post-breach DEM extending $2 \mathrm{~km} \times 0.6 \mathrm{~km}$ is shown in Fig. $5 \mathrm{~b}$. Here the red rectangle identifies the area of the December 2008 breach and encloses the washover deposited clearly seen in Fig. 2b, d.

\section{Model grid}

The grid setup for $\mathrm{XBeach}$ requires that the $\mathrm{X}$-axis is orientated approximately normal to the shoreline and the offshore boundary must be far enough offshore to allow space and time to generate the bound long waves. In the 2D area model, a variable resolution grid was set up using the recommended minimum resolution of 12 points per wavelength in the offshore regions. The grid resolution was increased to $3 \mathrm{~m}$ in the nearshore region. The offshore boundary of the model domain was extended using chart data ${ }^{4}$ beyond the region of available bathymetric survey data to a water depth of $-15 \mathrm{~m}$ ODM. A wave transformation using a MIKE Spectral Wave (SW) model of Dingle Bay provided wave data at the offshore boundary of the XBeach model from SEASTATES data at Location 1 (c. $-45 \mathrm{~m}$ ODM). The 2D XBeach model was then forced

\footnotetext{
${ }^{4}$ British Admiralty Nautical Chart 2789 Dingle Bay and Smerwick Harbour.
}

at the offshore boundary using time-varying JONSWAP spectra derived from the transformed wave data and the metocean data shown in Fig. 5 with a peak enhancement factor, $\gamma,=3.3$ and a directional spreading coefficient, $n_{s}=10$. The sediment grain size across the whole model domain is based on measurements (i.e. $D_{50}$ and $D_{90}=0.235$ and $0.341 \mathrm{~mm}$, respectively). To reduce the computational time the morphological acceleration factor (MORPH) of XBeach was set to a value of 10 and other parameter settings conformed to the most recent settings recommended by the model developers. ${ }^{5}$

\section{Modelling scenarios}

The modelling study comprised two related parts. In Part 1, the 2D XBeach model simulated the morphological changes that occurred during the 13-14 December 2008 breaching event. To define the starting bathymetry and topography, this study used the pre-storm DEM and compared XBeach predictions of storm impacts with the poststorm DEM. To simulate the breaching event, the XBeach model was run using metocean data for the 13-14 December 2008 storm.

In Part 2, XBeach was used to define the site-specific threshold conditions for dune recession, overwashing and breaching of the pre-storm morphology by looking at combinations of waves and tidal elevations most likely to occur at Rossbeigh with return periods defined by available data.

\section{Results and discussion}

\section{Part 1: 2D XBeach}

The XBeach model showed that during the simulated storm when wave height increased, a wide, well-defined surf zone developed on the ebb-tidal delta and along the proximal section of Rossbeigh where swash-aligned platforms are present (Fig. 2d). However, owing to wave energy dissipation on the ebb-tidal delta, the model showed that the distal section of Rossbeigh was sheltered. Not only does the simulation show the control on planform by large swell waves, it illustrates the ability of such shorelines to accommodate a large variation in swell wave sizes through energy dissipation on the shoreface and surf zone without any significant morphological change. Thus modification of the swell-related morphology requires waves to arrive at the shoreline without significant energy losses and/or produce a different energy dispersal pattern. These effects have been documented in previous XBeach modelling

\footnotetext{
${ }^{5}$ http://oss.deltares.nl/web/xbeach/home.
} 
studies of barrier overwashing (e.g. Roelvink et al. 2009) and for this reason are not discussed further here.

Using the same colour-scale on each sub-plot, results from the 2D XBeach depth-average model are shown in Fig. 6 and focus on the breach site indicated by the red rectangle in Fig. 5b. Figure 6a shows the changes in bed elevation between the observed pre- and post-storm DEMs (Fig. 5). For reference, the contour show the location of Rossbeigh spit prior to breaching (i.e. Fig. 5a). Figure 6a shows a region of erosion $O(-1 \mathrm{~m})$ associated with the

(a)

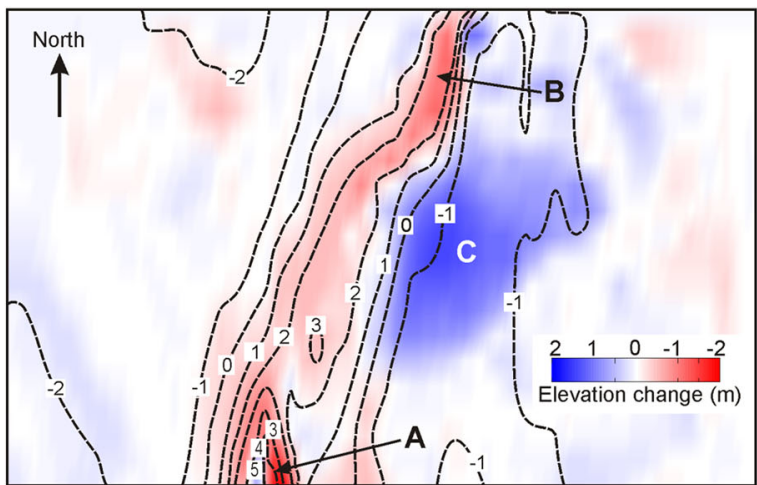

(b)

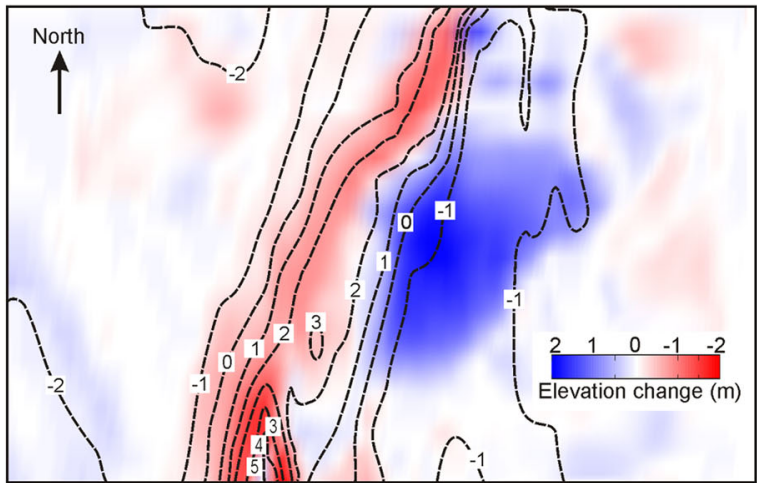

(c)

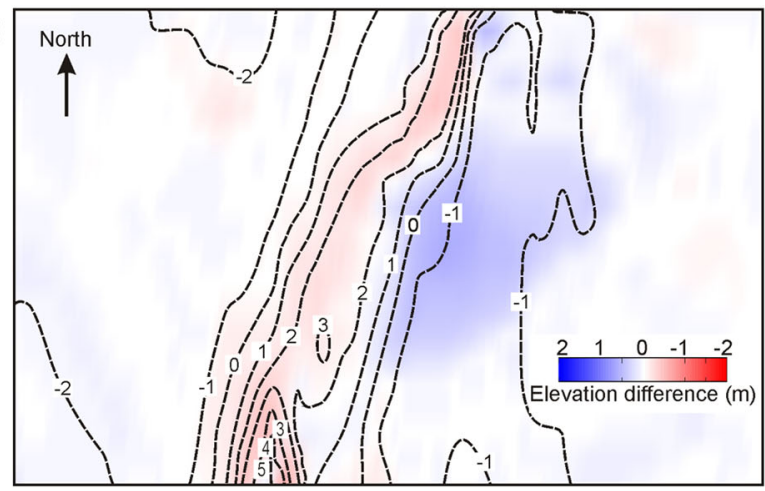

Fig. 6 Plots showing DEM elevation changes during the 13-14 December 2008 storm: a changes between the pre- and post storm DEMs; b changes between the pre-storm DEM and post-storm XBeach predictions; and $\mathbf{c}$ the differences between the measure poststorm DEM and the post-storm XBeach predictions. (Contours show elevation changes) breach running along the top of the spit and a corresponding region of accretion immediately behind the spit reflecting overwash deposits $O(1.5 \mathrm{~m})$ shown in Fig. 2d. Maximum erosion is seen at the northern terminus of the large dunes (location A) and at the northernmost end of the breach area (location $\mathrm{B}$ ). The maximum sediment accretion to the east of Rossbeigh is around $2 \mathrm{~m}$ (location C). Regions of erosion and accretion less than $0.5 \mathrm{~m}$ are observed to the west and east of the spit. Thus the evidence in Fig. 6a indicates a relatively simple morphological response of Rossbeigh to the storm characterised by the overwash event that acted to lower the spit and deposit mobilised sand to the east. The XBeach results therefore indicate a conservation of the total sand volume during the breach event.

Figure $6 \mathrm{~b}$ shows the changes in bed elevation between the observed pre-storm DEM and the storm-modified DEM predicted by the $2 \mathrm{D}$ XBeach model. In many respects the predicted areas of erosion and accretion are similar to those shown in Fig. 6a. However, the model appears to have a positive or negative bias across the majority of the model domain. Figure $6 \mathrm{a}, \mathrm{b}$ have many features in common, suggesting that the XBeach model performed well. However, the performance is better demonstrated in Fig. 6c which shows the difference between observed and predicted post-storm DEMs. Here areas shaded light blue (accretion) or light red (erosion) show regions where the XBeach model bed elevation predictions deviate from the observations. Figure $6 c$ shows that XBeach has a tendency to over-predict erosion on Rossbeigh Spit by values less than $0.5 \mathrm{~m}$. Accretion is also over-predicted on the eastern side of Rossbeigh.

In order to compare the measured post December 2008 storm beach and dune profiles along Rossbeigh Spit with those predicted by the 2D XBeach model, measured and predicted shore-normal beach profiles were examined at 30 locations along the shoreline. For illustrative purposes graphical results from the six locations along Rossbeigh shown in Fig. 7a are presented in Fig. 7b. For reference, Fig. $7 \mathrm{~b}$ also shows the position of the peak water level (tide plus surge) during the simulated storm period (13-14 December 2008). These beach profiles have been analysed to quantify: (a) the Brier skills score (BSS); (b) erosion above $0 \mathrm{~m}$ ODM; and (c) maximum dune recession distances.

The BSS values quantify the skill of the XBeach model in predicting post-storm beach and dune profiles ( $c f$. Sutherland et al. 2004). It compares the mean square difference between the prediction and observation with the mean square difference between baseline prediction and observation so that

$\mathrm{BSS}=1-\left[\frac{\left|x_{p}-x_{m}\right|^{2}}{\left|x_{b}-x_{m}\right|^{2}}\right]$ 

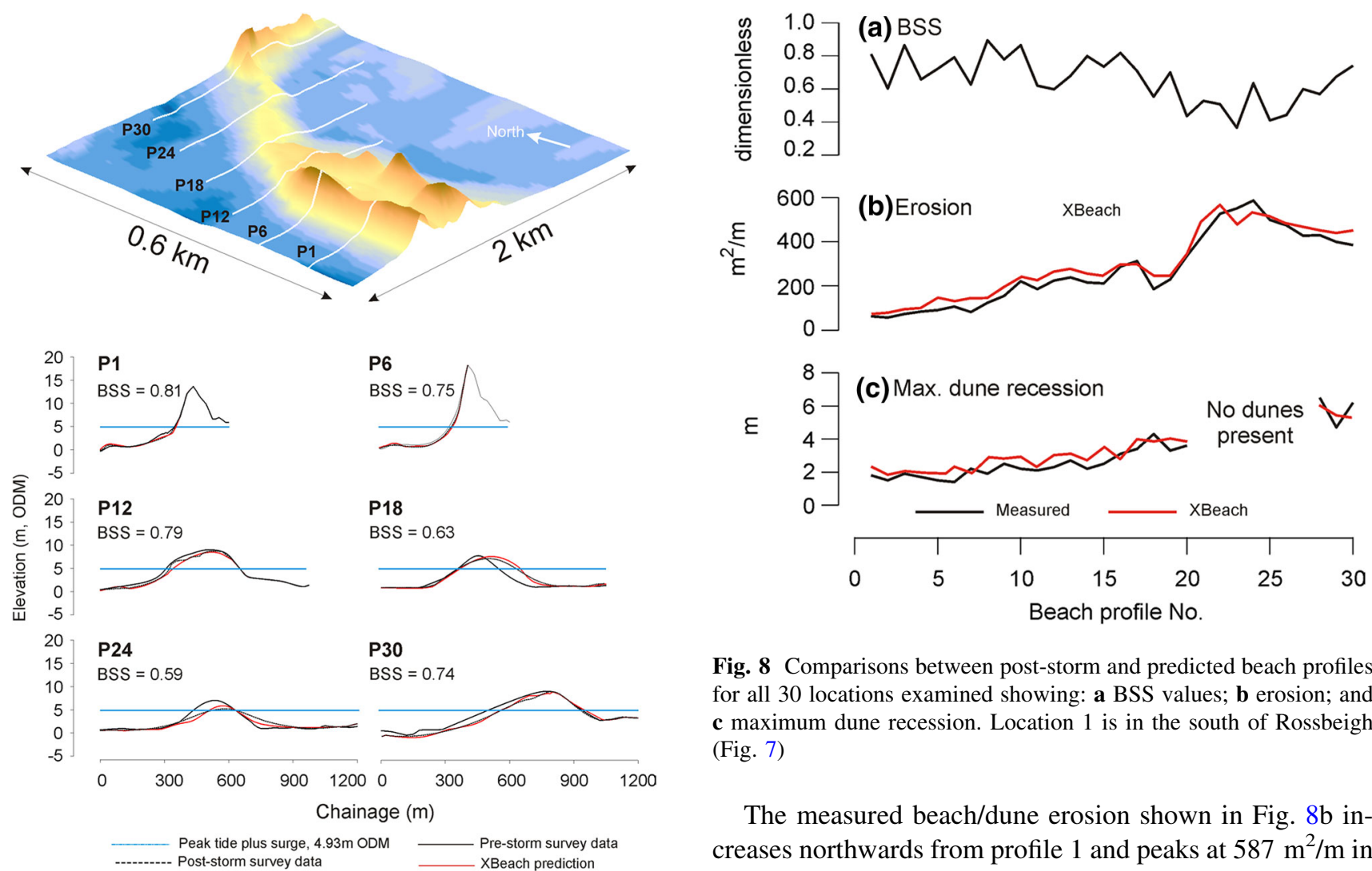

Fig. 8 Comparisons between post-storm and predicted beach profiles for all 30 locations examined showing: a BSS values; b erosion; and c maximum dune recession. Location 1 is in the south of Rossbeigh (Fig. 7)

The measured beach/dune erosion shown in Fig. $8 \mathrm{~b}$ increases northwards from profile 1 and peaks at $587 \mathrm{~m}^{2} / \mathrm{m}$ in the centre of the breach area (P24). Thereafter, beach/dune

Fig. 7 a Location of example beach profiles studied using the 1D XBeach model of the 13-14 December 2008 storm; and b results from the 1D XBeach profile study (locations shown in Fig. 7) of showing from the DEMs the pre-storm and post-storm profiles and the corresponding post-storm XBeach predictions. Also shown for reference is the peak tide plus surge water level relative to each profile

where $x_{p}$ is the post-storm beach profile predicted by the model, $x_{m}$ is the measured post-storm beach profile and $x_{b}$ is the pre-storm beach profile (baseline). Perfect agreement gives a BSS score of 1 , and negative values indicate that predictions are worse than the baseline value. An interpretation of BSS values is provided by Van Rijn et al. (2003) where $0<$ BSS $<0.3, \quad 0.3<$ BSS $<0.6$, $0.6<\mathrm{BSS}<0.8$, and BSS $>8$ indicated poor, reasonable/fair, good and excellent, respectively.

For P1-P17 in the southern region of Rossbeigh, BSS values fall in the range $0.59-0.89$ with an average value of 0.74 (Fig. 8a) demonstrating 'good' agreement. In the region of the breach (P18-P27) BSS values fall in the range $0.36-0.70$ and the average BSS value reduces to 0.52 (i.e. 'reasonable/fair' agreement). At the northern end of Rossbeigh, P28-P30 have BSS values in the range 0.56-0.74 and an average BSS value of 0.66 ('good'). These BSS values demonstrate that the XBeach model predictions are good or excellent for more than $70 \%$ of the profiles. erosion reduces to $c .400 \mathrm{~m}^{2} / \mathrm{m}$. At most locations examined, the beach/dune erosion predicted by XBeach is $O(15 \%)$ greater than the measured values and shows a similar increasing trend northwards towards the breach and a similar decrease beyond P27.

The storm response modelling of Rossbeigh Spit has identified a number of areas where increased levels of dune recession might be expected to occur. These areas correspond relatively well with the plots of historical dune recession. Measured maximum dune recession distances shown in Fig. $8 \mathrm{c}$ increase in a northwards direction along Rossbeigh from $c .2 \mathrm{~m}$ around $\mathrm{P} 1$ to $c .5 \mathrm{~m}$ at $\mathrm{P} 30$. As there are no clearly defined dunes present between P20 and P28 it has not been possible to define a recession distance. However, this region is characterised by the highest erosion due to overwash and the general lowering of the upper beach profile (as shown in Fig. 7, P24). Again XBeach is shown to over-estimate dune recession by around $15 \%$. Nevertheless, the magnitudes of dune recession modelled (Fig. 8c) and the estimated historical rates of recession in these areas in the range 4 and $9 \mathrm{~m} / \mathrm{yr}$ indicate that the modelled values are not wholly unrealistic and a level of confidence can be afforded to them. The dune recession distances between P5 and P11 on the southern section of the spit of $c .2 \mathrm{~m}$ are not well-supported by the historical evidence of erosion which indicates that the area is relatively stable. It is not possible to say whether this 
discrepancy arises from unknown errors in the pre-storm DEM used in the simulation or from inaccuracies associated with the XBeach model.

\section{Part 2: 1D XBeach}

With the XBeach model now validated, Part 2 of the modelling study uses 1D XBeach simulations to first examine how well the storm impact scale proposed by Sallenger (2000) performs at Rossbeigh. It then uses 2D XBeach results to establish the combination of waves and tidal conditions specific to Rossbeigh that resulted in: (1) dune erosion of more than $2 \mathrm{~m}$; (2) intermittent overwashing for more than one hour; and (3) breaching as observed in December 2008.

Based on field observations of sandy barrier islands, Sallenger (2000) presents a storm impact scale which takes account of tide/surge, waves and wave runup as well as beach geometry. The impact classification is based on four parameters: $R_{\text {high }}$ and $R_{\text {low }}$, defining the upper and lower vertical limit of the swash margin during an event, respectively; and $D_{\text {high }}$ and $D_{\text {low }}$ defining the maximum and minimum elevation of the dunes or berm, respectively. Using these parameters, four storm impact regimes are defined: (a) the swash regime (Impact Level 1) where $R_{\text {high }}$ ' $D_{\text {high }}=0$ to $D_{\text {low }} / D_{\text {high }}$; (b) the impact regime (Impact Level 2) where $R_{\text {high }} / D_{\text {high }}=D_{\text {low }} / D_{\text {high }}$ to 1 ; (c) the overwash regime (Impact Level 3) where $R_{\text {high }} / D_{\text {high }}>1$ and $R_{\text {low }} / D_{\text {high }}<1$; and the inundation regime (Impact Level 4), where $R_{\text {high }} / D_{\text {high }}>1$ and $R_{\text {low }} / D_{\text {high }}>1$. Although being simplistic, storm impacts defined by these parameters are considered to be appropriate for the present study since the model results are by definition only approximations to reality.

Values for $D_{\text {high }}$ and $D_{\text {low }}$ were obtained from the prestorm DEM, and time-series of the waterline position extracted from the XBeach model were analysed to define $R_{\text {high }}$ and $R_{\text {low }}$ at 10 min intervals during the 13-14 December 2008 storm simulation. Broadly speaking it was found that initial dune toe erosion predicted south of the beach area (e.g. $D_{\text {low }} / D_{\text {high }}=0.17$ to 0.37 ) occurred when $R_{\text {high }} / D_{\text {high }}>c$. 0.6. Overwashing of the breach area (Fig. 5b) began when $R_{\text {high }} / D_{\text {high }}=c .1 .1$ and, owing to the pre-storm beach geometry where dunes were absent, inundation occurred shortly thereafter $\left(R_{\text {high }} / D_{\text {high }}=\right.$ c. 1.2). The XBeach model predictions of dune erosion, overwash and inundation (breaching) thresholds therefore agreed broadly with the Sallanger storm impacts classification.

At Rossbeigh it is clear from both the historical records of erosive events (e.g. Cooper et al. 2004; O'Shea and Murphy 2013), and from the XBeach model results reported in this study, that significant erosion, overwashing and breaching are only accomplished during spring tide (plus surge) conditions when the combined peak tide and surge water levels, $h_{\text {max }}$ allow larger than normal waves to reach and attack the upper part of the beach. Part 2 acknowledges this and various combinations of $H s$ and $h_{\max }$ were tested over two spring tidal cycles (c. $12.5 \mathrm{~h}$, a typical storm duration) using the XBeach model. The matrix of model runs shown in Table 1 . Here the $H s$ values indexed 1, 2, 3 and 4 correspond to 1:1, 1:5, 1:10 and 1:50 year return period events defined by previous analyses of wave records (Orford et al. 1999; Cooper et al. 2004; Vial 2008; Sala 2010; and Olbert and Hartnett 2010).

A further very important factor known to determine the amount of erosion at Rossbeigh and elsewhere (e.g. Esteves et al. 2011) concerns the duration of a particular storm. Therefore in Part 2, storm simulations spanning four tidal cycles (c. $25 \mathrm{~h}$ ) were also examined (Table 2) to assess the importance of storm length. Although it is noted that storm duration at Rossbeigh can sometimes exceed $25 \mathrm{~h}$, for practical reasons concerning the number of model runs and associated time, storms lasting more than $25 \mathrm{~h}$ were not investigated.

In the present tests a peak wave period, $T p$, of $16 \mathrm{~s}$ was selected as being representative of typical storm scenarios at Rossbeigh. Additional test results for wave periods in the range 10-19 s are discussed below with regards to model sensitivity. In common with the model runs in Part 1, the starting morphology in XBeach model runs in Part 2 was defined by the pre-storm DEM previously described.

Colour coding in Tables 2 and 3 is used to identify the three morphological threshold conditions for Rossbeigh believed to be representative of the Sallenger collision (Impact Level 2), overwash (Impact Level 3) and inundation (Impact Level 4) regimes. Note that $h_{\max }$ and $H s$ pertaining during the 13-14 December 2008 storm, and applied in Part 1 , are indicated by bold red text in both tables.

Plots in Fig. 9 show the relationship between $h_{\text {max }}$ and the offshore critical significant wave height, $H s_{\text {crit }}$ that define Impact Levels 2, 3 and 4 for simulated storm durations of: (a) $12.5 \mathrm{~h}$; and (b) $25 \mathrm{~h}$. Irrespective of the Impact Level, Fig. 9a shows a non-linear decrease in $H s_{\text {crit }}$ with increasing in $h_{\max }$ values for simulated storm duration of 12.5 h. Similar relationships are also shown in Fig. 9b for simulated storm duration of $25 \mathrm{~h}$. However, in this case, threshold $H s_{\text {crit }}$ for a given $h_{\text {max }}$ values for Impact Levels 2, 3 and 4 are lower than those for the $12.5 \mathrm{~h}$ storm simulation. This simply reflects the morphological changes to Rossbeigh occurring during the first couple of tidal cycles which lowered the beach elevation allowing smaller waves during the later parts of the $25 \mathrm{~h}$ simulations to be more effective. It is noted that storm waves with Tp of $16 \mathrm{~s}$ resulted in a $45 \%$ increase in dune recession compared to storm with $T p$ of $10 \mathrm{~s}$. 
Table 1 Predicted response of Rossbeigh breach area (Fig. 5b) to combinations of waves and peak water elevations over two tidal cycles $(c .12 .5 \mathrm{~h})$ with $T p$ of $16 \mathrm{~s}$

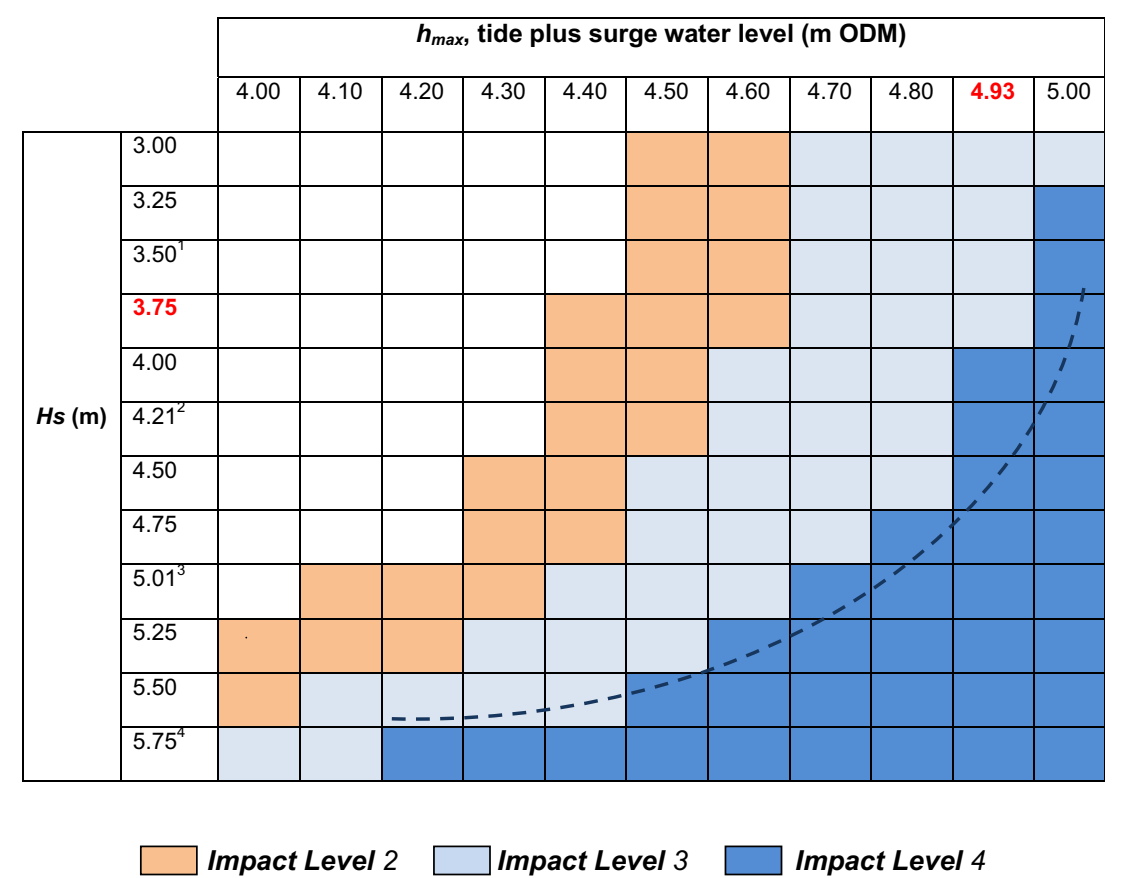

Bold red text shows $h_{\max }$ and $H s$ pertaining during the 13-14 December 2008 storm

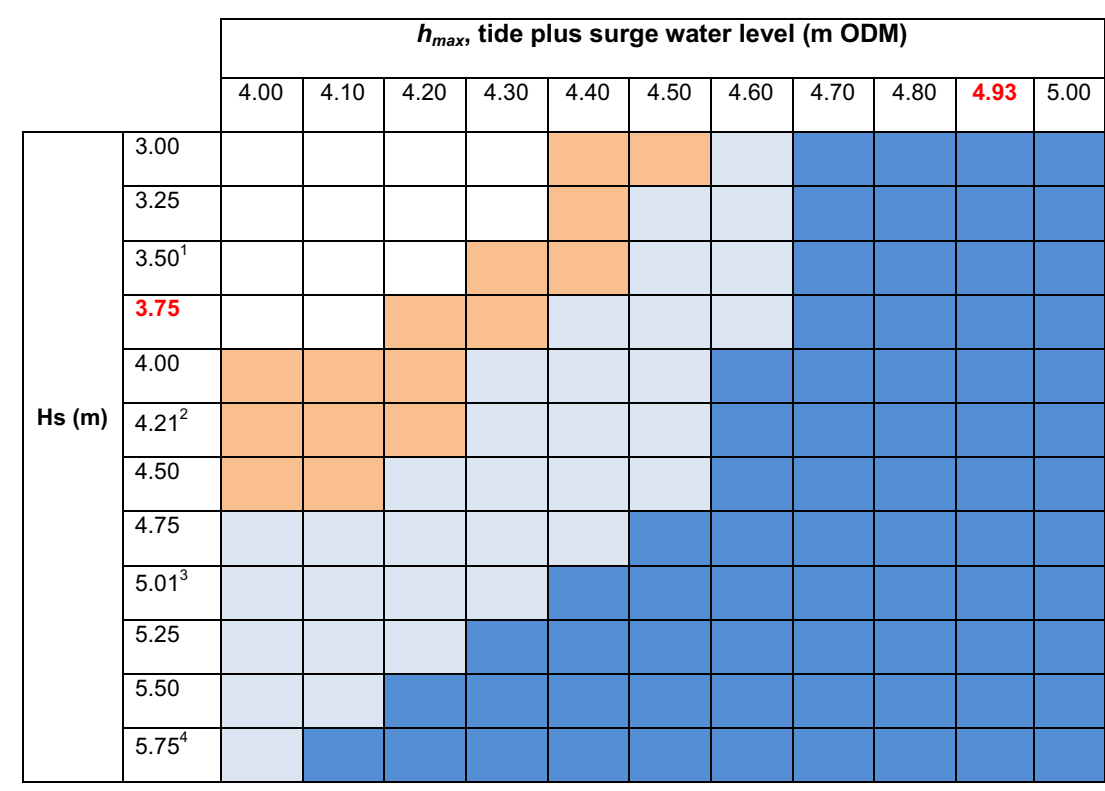

Impact Level $2 \square$ Impact Level $3 \quad \square$ Impact Level 4

Bold red text shows $h_{\max }$ and $H s$ pertaining during the 13-14 December 2008 storm
For peak water levels in the range $4.0 \mathrm{~m}<h_{\max }<5.0 \mathrm{~m}$ ODM, the statistical significance of relationships between $h_{\max }$ and $H s_{\text {crit }}$ can be described using a second order polynomial expression (Fig. 9) in the form

$H s_{c r i t}=a \cdot h_{\max }^{2}+b \cdot h_{\max }+c$.
Values of the coefficients $a, b$ and $c$ and the product moment correlation coefficient $R^{2}$ are given in Table 3. In all cases Student's $t$ statistic demonstrated that $R^{2}$ values were statistically significant at the $95 \%$ confidence interval or better. While Eq. 4 can be used to define the site specific 
Table 3 Regression coefficients $a, b$ and $c$, and product moment correlation coefficients $R^{2}$ for $H s$ on $h_{\max }$ (Fig. 9) defining storm Impact Levels 2, 3 and 4 for: (a) simulated storm duration c. $12.5 \mathrm{~h}$; and (b) simulated storm duration c. $25 \mathrm{~h}$

\begin{tabular}{lllrr}
\hline Impact level & $a$ & $b$ & \multicolumn{1}{c}{$c$} & \multicolumn{1}{c}{$R^{2}$} \\
\hline (a) & & & & \\
2 & -9.9 & 79.8 & -155.5 & 0.91 \\
3 & -5.9 & 48.5 & -92.7 & 0.95 \\
4 & -4.8 & 40.9 & -81.9 & -0.94 \\
(b) & & & & \\
2 & -2.9 & 21.3 & -35.3 & 0.85 \\
3 & -2.4 & 17.3 & -26.1 & 0.88 \\
4 & -7.4 & 62.3 & -120.5 & 0.78 \\
\hline
\end{tabular}

(a)

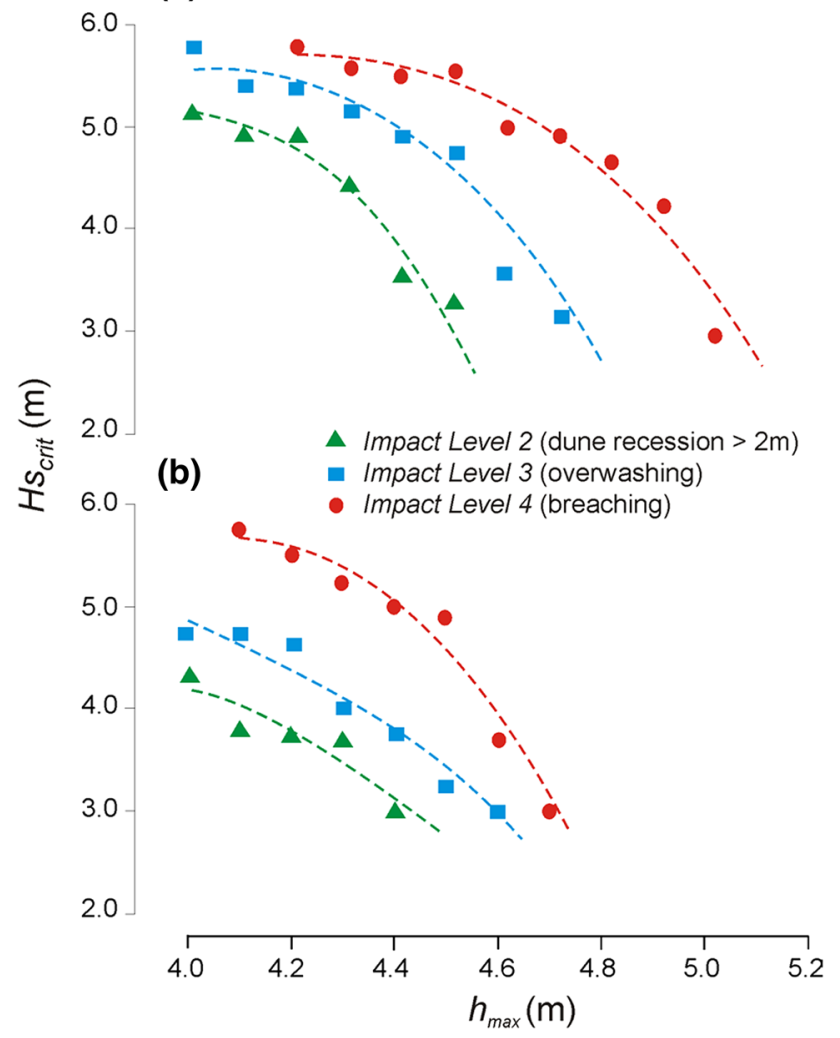

Fig. 9 Relationships between $h_{\max }$ and $H s$ defining storm Impact Levels 2, 3 and 4 for: a simulated storm duration $c .12 .5 \mathrm{~h}$; and b simulated storm duration c. $25 \mathrm{~h}$

critical conditions for Impact Levels 2, 3 and 4 at Rossbeigh, their use at other sites must be treated with caution.

\section{Conclusions}

The XBeach model has been applied to simulate the December 2008 breaching event at Rossbeigh Spit in the west of Ireland. With good model performance demonstrated, it has then been applied to investigate the significance and relative importance of the parameters associated with storm events has examined the threshold conditions at Rossbeigh leading to dune recession, overwash and breaching.

The processes and impacts occurring during storms along the southern coast of Rossbeigh are considered to fall within the 'collision regime' of Sallenger (2000) with high levels of dune recession at the dune base around the recurve point and towards the northern end of the recurve section. The locations agree broadly with known historical erosion areas. Predicted dune recession values of $c .5 \mathrm{~m}$ appear to be realistic as historical rates of recession in these areas have been shown to lie between 4 and $9 \mathrm{~m} / \mathrm{yr}$ (O’Shea and Murphy 2013).

The various storm scenarios modelled with XBeach have shown that the exposure of Rossbeigh Spit to the high energy Atlantic swell wave characterised by wave periods of around $16 \mathrm{~s}$, is a critical factor in driving erosion processes at Rossbeigh. Storm waves with $T p$ of $16 \mathrm{~s}$ resulted in a $45 \%$ increase in dune recession compared to storm with $T p$ of $10 \mathrm{~s}$. Local storm waves are unlikely therefore to cause significant morphological impacts along Rossbeigh. Increasing the period further to $19 \mathrm{~s}$ had no detectable effect on dune recession owing to wave energy dissipation offshore.

XBeach modelling has demonstrated that storm duration is an important factor determining the magnitude of storm impacts at Rossbeigh. Comparisons between erosion attributable to a 1:5 year storm event lasting c. $25 \mathrm{~h}$ and a 1:50 year event lasting c. $12.5 \mathrm{~h}$ indicated that an increase in dune recession of around $80 \%$. The results imply that extreme offshore waves will not necessarily cause a significant increase in erosion at the shoreline owing to dissipative nature of Rossbeigh beach. However, storms of sustained duration or storms occurring in rapid succession with little time for shoreline recovery are important events driving morphological change.

While wave period and direction were approximately the same, the offshore significant wave height of the 5 December 2008 storm was $72 \%$ larger than the 13-14 December 2008 storm that caused the breach. However, the occurrence of the 5 December 2008 storm during neap tides illustrates well that storm impacts on Rossbeigh are highly dependent on water level. Similarly, Pye and Blott (2008) and Esteves et al. (2011) show that dune erosion is strongly correlated with elevated water levels and/or storm duration along the Sefton coast in northwest England.

Multiple XBeach model runs have examined the morphological impact of various combinations of $h_{\max }$ and $H s$ conditions. In broad terms, for a given peak water level during two tides at Rossbeigh (a typical storm duration), the critical significant wave height, $H s_{\text {crit }}$ for Impact Level 2 on the pre-storm December 2008 barrier is defined by the expression $H s_{c r i t}=a \cdot h_{\max }^{2}+b \cdot h_{\max }+c$ where the coefficients $a, b$ and $c$ are site specific. At present no physical 
meaning can be attached to this equation. In order to develop an expression that can be tested at alternative locations work is now required to link the coefficients to site specific parameters. Initial work suggests that coefficient $a$ might be inversely related to bottom friction, coefficient $b$ to the depth of wave breaking, and coefficient $c$ to a threshold wave height for HW impact. Further, the inclusion of storm duration would widen the applications for this equation.

The model results indicate that events giving rise to significant storm impact are likely to become more frequent for dune systems with rising sea levels. This demonstrates the importance of this research in relation to climate change and to other regions.

The XBeach model has been shown to be a powerful and useful tool for assessing dune erosion and overwash for relatively short time-scale storm events. Contemporary evidence of barrier breaching is rare and the study has value in demonstrating that a numerical model can reproduce the correct spatial distribution of the most important key morphological impacts albeit with questionable accuracy. Further by examining a naturally dynamic coastal system the study has scientific value and addresses a number of concerns associated with flooding, economic value and habitat.

It is noted that this study has only considered present day sea levels. Although it has been shown that Rossbeigh can accommodate larger storms through a variable surf zone width, it is thought likely that breaching events will become more frequent in response to rising sea levels due primarily to wave action at higher elevations across beach and dune profiles. Further work is now required to assess climate change impacts and whether or not such a system can adjust with sufficient speed to accommodate sea level rise.

The application of XBeach has potential use for assessing vulnerability of present day barriers and beaches to overwashing and breaching for a range of present day and future storm scenarios. It can contribute therefore to coastal management and planning as well as providing an early warning of potential erosion and structural damage and ensuing threat to lives and property.

Acknowledgments Thanks are extended to: Michael O'Shea (University College Cork) for the help with access and collecting data; David Lambkin (ABPmer) for providing SEASTATES predictions for Dingle Bay; and Jack Shipton (ABPmer) for tidal predictions from Delft Dashboard.

\section{References}

Bird ECF (1985) Coastline changes: a global review. Wiley, Chichester, p 219

Carter RWG (1988) Coastal environments. Academic Press, London
Cooper JAG, Jackson DWT, Navas F, McKenna J, Malvarez G (2004) Identifying storm impacts on an embayed, high-energy coastline: examples from western Ireland. Mar Geol 210:261-280

Devoy RJN (2009) Iveragh's coasts and mountains. In: Crowley J, Sheehan J (eds) The Iveragh peninsula: a cultural atlas of the Ring of Kerry. Cork University Press, Cork

Dorandeu J, Le Traon P (1999) Effects of global mean atmospheric pressure variations on mean sea level changes from TOPEX/ Poseidon. J Atmos Ocean Technol 16(9):1279-1283

Esteves LS, Brown JM, Williams JJ, Lymbery G (2011) Quantifying thresholds for significant dune erosion along the Sefton Coast, Northwest England. Special Issue on "Thresholds for storm impacts along European coastlines", Geomorphology. doi:10. 1016/j.geomorph.2011.02.029

Giese G, Adams MB, Keon T, Mague ST (2009) Observations of a pre-migration phase in a natural tidal inlet migration 'Cycle'. In: Northeast Beaches Conference, Northeast Shore and Beach Preservation Association, Woods Hole, September 21-23, 2009

Gourlay MR (1968) Beach and dune erosion tests. Delft Hydraulics Laboratory, Report No. M935/M936

Gracia V, García M, Grifoll M, Sánchez-Arcilla A (2013) Breaching of a barrier beach under extreme events: the role of morphodynamic simulations. In: Conley DC, Masselink G, Russell PE, O'Hare TJ (eds) Proceedings 12th International Coastal Symposium (Plymouth, England). Journal of Coastal Research. Special Issue No. 65, pp 951-956. ISSN 0749-0208

Kraus NC (2003) Analytical model of incipient breaching of coastal barriers. Coast Eng J 45:511-531

Kraus NC, Wamsley TV (2003) Coastal barrier breaching. Part 1: overview of breaching processes, coastal and hydraulics laboratory technical note ERDC/CHL CHETN IV-56, U.S. Army Engineer Research and Development Center, Vicksburg, MS

Larson M, Wise RA, Kraus NC (2004) Coastal overwash: Part 2, Upgrade to SBEACH (No. ERDC/CHL-CHETN-XIV-14). Engineer Research and Development Center Vicksburg MS Coastal \& Hydraulics Lab

Lozano I, Devoy RJN (2000) Storm activity along the Atlantic coastlines of Europe: a study for the last four decades and a 2xCO2 experiment (ECHAM4 T106). Geophysical Research Abstracts 2

Lozano I, Devoy RJN, May W, Andersen U (2004) Storminess and vulnerability along the Atlantic coastlines of Europe: analysis of storm records and of greenhouse gases induced climate scenario. Mar Geol 210:205-225

Masselink G, Short AD (1993) The effect of tide range on beach morphodynamics and morphology: a conceptual beach model. J Coast Res 9:785-800

McCall RT (2008) The longshore dimension in dune overwash modelling. Development, verification and validation of XBeach. MSc Thesis, Delft University of Technology, Delft, The Netherlands

O'Shea M, Murphy J (2013) Predicting and monitoring the evolution of a coastal barrier dune system post-breaching. J Coast Res 29(6A):38-50

O'Shea M, Murphy J, Sala P (2011) Monitoring the morphodynamic behaviour of a breached barrier beach system and its impacts on an estuarine system. OCEANS'11, IEEE Conference, Santander, Spain

Olbert AI, Hartnett M (2010) Storms and surges in Irish coastal waters. Ocean Model 34:50-62

Orford JD, Cooper JAG, McKenna J (1999) Mesoscale temporal changes to foredunes at Inch Spit, south-west Ireland. Zeitschrift für Geomorphologie 43:439-461

Pye K, Blott SJ (2008) Decadal-scale variation in dune erosion and accretion rates: an investigation of the significance of changing 
storm tide frequency and magnitude on the Sefton coast, UK. Geomorphology 102(3):652-666

Roelvink JA, Reniers A, van Dongeren A, van Thiel de Vries J, McCall RT, Lescinski J (2009) Modelling storm impacts on beaches, dunes and barrier islands. Coast Eng 56:1132-1152

Roelvink JA, Reniers A, van Dongeren A, de Vries J, Lescinski J, McCall R (2010) XBeach model description and manual. Unesco-IHE Institute for Water Education, Deltares and Delft University of Technology, Rept November 2009, p 106

Sala P (2010) Morphodynamic evolution of a tidal inlet mid-bay barrier system. MSc thesis, University College Cork, Cork, Ireland

Sallenger AH (2000) Storm impact scale for barrier islands. J Coast Res 16(3):890-895

Sánchez-Arcilla A, Jiménez JA (1994) Breaching in a wavedominated barrier spit: the Trabucador Bar (Northeastern spanish coast). Earth Surf Proc Land 19:483-498

Stockdon HF, Sallenger AH, Holman RA, Howd PA (2007) A simple model for the spatially-variable coastal response to hurricanes. Mar Geol 238:1-20
Sutherland J, Peet AH, Soulsby RL (2004) Evaluating the performance of morphological models. Coast Eng 51(8-9):917-939

Terchunian AV, Merkert CL (1995) Little Pikes Inlet, Westhampton, New York. J Coast Res 11:697-703

Van Dorn WG (1953) Wind stresses on an artificial pond. J Mar Res 12:216-249

Van Rijn LC, Walstra DJR, Grasmeijer B, Sutherland J, Pan S, Sierra JP (2003) The predictability of cross-shore bed evolution of sandy beaches at the time scale of storms and seasons using process-based profile models. Coast Eng 47(3):295-327

Van Thiel de Vries JSM (2009) Dune erosion during storm surges. PhD Thesis, IOS Press, The Netherlands, ISBN: 978-1-60750041-4, p 200

Vial T (2008) Monitoring the morphological response of an embayed high energy beach to storms and Atlantic waves. Master's Thesis, University College Cork, Cork, Ireland 